\title{
Consumer attitudes towards the mountain product label: Implications for mountain development
}

\author{
BASSI Ivana1 ${ }^{\text {iD }}$ https://orcid.org/oooo-0001-9046-8958; e-mail: ivana.bassi@uniud.it

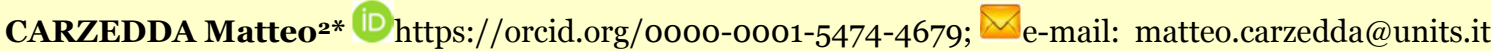

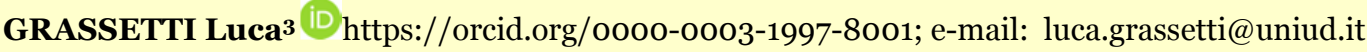

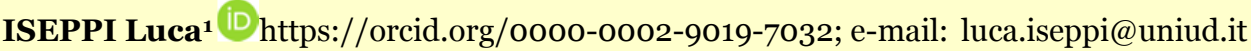 \\ NASSIVERA Federico ${ }^{1}$ iD https://orcid.org/oooo-0003-0125-956X; e-mail: federico.nassivera@uniud.it \\ * Corresponding author \\ 1 Department of Agricultural, Food, Environmental and Animal Sciences, University of Udine, via delle Scienze 206, \\ Udine, Italy \\ 2 Department of Economics, Business, Mathematics and Statistics, University of Trieste, via Tigor 22, Trieste, Italy \\ 3 Department of Economics and Statistics, University of Udine, via Tomadini 3o/A, Udine, Italy
}

Citation: Bassi I, Carzedda M, Grassetti L, et al. (2021) Consumer attitudes towards the mountain product label: Implications for mountain development. Journal of Mountain Science 18(9). https://doi.org/o.1007/s11629-020-6616-z

(C) The Author(s) 2021.

\begin{abstract}
To protect and promote the originality and authenticity of mountain foodstuffs, the European Union set Regulation No 1151/2012 to create the optional quality term "mountain product". Our research aimed at exploring the attractiveness of the mountain product label for consumers, considering both attitude towards the label itself and purchase intentions. We propose a model to investigate relationships between four latent constructs mountain attractiveness, mountain food attractiveness, attitude towards the mountain product label, and purchase intention - which have been tested, thus confirming the statistical relevance of the relationships. All 47 items selected for describing the latent constructs are suitable for this purpose. Ridge and LASSO results also show that 17 items of the first three constructs are relevant in explaining purchase intentions. Some contextual variables, such as age, income, geographical origin of consumers, and knowledge of mountain products and mountains for
\end{abstract}

Received: 07-Dec-2020

Revised: 05-Jun-2021

Accepted: 16-Jul-2021 tourism purposes, can positively influence consumers' behavior. These findings could support the design of mountain development strategies, in particular marketing actions for both the product and the territory.

Keywords: Mountain product label; Consumer attitudes; Purchase intentions; Structural Equation Model (SEM); LASSO regression.

\section{Introduction}

Mountain food products are distinctive for the characteristics of their ingredients, the way they are farmed, and the use of traditional production and processing methods. The European Union (EU) Regulation No 1151/2012, the so-called "Quality Package", defines the legal framework to protect the originality and authenticity of these and other agricultural products and foodstuffs. Together with the update and definition of geographical indications 
and quality schemes, namely the Protected Designation of Origin (PDO), Protected Geographical Indication (PGI), and Traditional Specialties Guaranteed (TSG), the regulation sets the grounds and boundaries to use specific, additional quality terms, such as "Mountain Product". More in detail, article 31 of the regulation allows the use of this denomination only to describe products whose ingredients and raw materials come essentially from mountain areas, as defined in accordance with EU Regulation No 1257/1999 on rural development; moreover, in the case of processed products, processing should also take place in mountain areas. Conditions and limits to the use of this new label have been further elaborated in the Delegated Regulation No 665/2014 (Bentivoglio et al. 2019; Bonadonna et al. 2015; Finco et al. 2017). Ancillary to the EU framework, the Decree of the Italian Ministry of Agriculture, Food and Forestry of 26/7/2017 defines and regulates implementation procedures at the national level, as, for instance, the possibility to establish an identification logo to the benefit of operators participating in the "mountain product" quality scheme. The Italian logo was launched in early 2018 (www.politicheagricole.it).

By promoting mountain food products, the EU approach aims at supporting the mountain agrifood sector and the diversification of local economies, providing quality guarantees to consumers, promoting tourism, protecting the environment, thus pushing the adoption of sustainable development models in European mountain regions. Indeed, economic operators are likely to benefit from the opportunity to exploit the positive image of mountains and increase the value-added of their products, primarily foodstuffs, but also related products and services such as tourism. To a different extent, consumers benefit from this new quality scheme, which guarantees the origin of the mountain product (Bonadonna 2016; McMorran et al. 2015).

Many scholars have already focused on some issues concerning mountain products and the EU label. Martins and Ferreira (2017) found that the use of the optional quality term "mountain food" could encourage better recognition of mountain foods by consumers and thus improve the economic and market performance of farms. Bonadonna (2016) and Bonadonna et al. (2017) analysed the level of awareness and interest of some farms in the North-Western Alps in the EU label. Bonadonna et al. (2015) and Bonadonna and Duglio
(2016) investigated the applicability of the EU regulation's rules regarding the production of few traditional kinds of cheese from small mountain areas in Piedmont. Bentivoglio et al. (2019) studied the main protocols used to assess the authenticity of dairy and meat products, which are the most widespread mountain food products. Finco et al. (2017) carried out two surveys, one among producers and one among retailers, and found that although the EU label is generally accepted, it is not yet well known, probably due to a lack of communication. To a similar extent, Sanjuan and Khliji (2016) conclude that consumers, in particular in urban areas, appear less aware of and interested in the EU food mountain labelling.

While scholars have addressed some important questions, others remain unanswered, particularly those concerning consumer behavior: What are consumers' attitudes towards the mountain product label? And what are their purchasing intentions?

In order to fill these information gaps, our study proposes four latent constructs - mountain attractiveness, mountain food attractiveness, attitude towards the mountain product label, and purchase intention - and analyses the relationships between them. Our results show that mountain attractiveness, mountain food attractiveness and mountain product label attitude positively influence the intention to buy mountain food products. In addition to these findings, we identify contextual variables, such as the age of consumers, which further affect purchase intentions and should therefore carefully considered when planning marketing strategies for mountain food products.

\section{Research Framework}

This study intends to explore the relationship between the behavioural intention to purchase mountain food products (Purchase Intention) and three personal and psychological dimensions (mountain attractiveness, mountain food attractiveness, mountain product label attitude), related to the individual perception of and attitude towards mountain regions and mountain products. To describe and measure the four constructs, 47 items and related validated scales were selected from the relevant literature on mountain fruition and consumer studies and adapted to appropriately suit the study topics, i.e. mountain, mountain food and 
the specific label.

\subsection{Mountain attractiveness (MA)}

As demonstrated by the vast literature on this subject (e.g. Brida et al. 2010; Charters \& Saxon 2007; Debarbieux \& Price 2008; Kuščer \& Mihalič 2015; Nepal \& Chipeniuk 2005), mountain regions are important tourism destinations. According to Silva et al. (2013), the attractiveness of mountains leads to a tourism demand corresponding to about $20 \%$ of global tourist flows. This specific tourism branch encompasses a variety of components and motivations, such as pleasure, adventure, social interaction, living in a different environment. Tourists' different backgrounds and interests lead to diverse interpretations of what makes a tourism product attractive (Kim et al. 2012; Oh et al. 2007; Stamboulis \& Skayannis 2003).

Mountains are natural assets and repositories of cultural heritage, social and historical sites, places to relax, recreation facilities, nature-based activities (e.g. hiking, trekking), and a variety of other resources and related opportunities. These destination attractions, both natural and manmade, possibly unique, are the core determinants of destination attractiveness, also for mountain areas (Navrátil et al. 2013; Taher et al. 2015; Vengesayi et al. 2009) and can be turned into value-in-use for tourists (Chekalina et al. 2018). Furthermore, the various assets influence the destination development and shape the capacity for being innovative, impacting destination development itself. Indeed, a destination needs to constantly adapt to external changes, such as those in consumer demand, to mitigate their negative effects or emphasize those favorable, thus bolster destination attractiveness and competitiveness (Kuščer \& Mihalič 2015).

This study investigates the causal relationships between destination attractiveness, place attachment, and environmentally responsible behavior to promote the sustainable development of island tourism. Nine items were selected to describe mountain attractiveness, as shown in Table 1 . The item selection provides a structured representation of the multiple aspects of mountain attractiveness, in line with previously published analytical frameworks on mountain tourism (Matei et al. 2019; Silva et al. 2018). Cheng et al. (2013) considered the destination attractiveness construct and explained it by testing several items, e.g. unique eco-environment of the island, historical vestiges and temple culture, wellappointed accommodation and restaurants, unique local specialties and souvenirs. The attractiveness of mountain forest was the focus of De Meo et al. (2015), who described people's perception and preferences regarding the recreational value of forests. In asking interviewees "what is important to find in a forest", the authors proposed various facilities/infrastructure such as paths, sports equipment, places of historical and religious interest, and so on. Finally, Murphy et al. (2000) focused on destination product as leverage to bolster destination competitiveness. They examined the relationship among five constructs: environment, infrastructure, quality, value and a tourist's intention to return. As for the first two, they selected eight variables: pleasant climate, attractive scenery, clean villages, heritage ambience, friendly people, good food, interesting attractions and good hotels.

\subsection{Mountain food attractiveness (MFA)}

There is a strong link between local food and the intention to (re)visit a destination, also for mountain destinations. Indeed, tourists appreciate local specialties, which, together with other local amenities, contribute to destination attractiveness (Alderighi et

Table 1 Mountain attractiveness construct. Items used in the questionnaire and sources for the standardized scales.

\begin{tabular}{|c|c|c|}
\hline Items & Code & Source \\
\hline I think that the mountains have a unique eco-environment (climate, cleanness) & MA1 & \multirow{9}{*}{$\begin{array}{l}\text { Cheng et al. } 2013 \\
\text { De Meo et al. } 2015 \\
\text { Murphy et al. } 2000\end{array}$} \\
\hline I think that the mountains have special village culture (friendly people) & MA2 & \\
\hline $\begin{array}{l}\text { I think that the mountains have historical vestiges (heritage ambience, places of } \\
\text { historical and religious interest) }\end{array}$ & MA3 & \\
\hline I think that the mountains have unique local specialties (good food) and souvenirs & MA4 & \\
\hline I think that the mountains have beautiful/attractive scenery & MA5 & \\
\hline I think that the mountains have well-developed environment management & MA6 & \\
\hline $\begin{array}{l}\text { I think that the mountains have well-appointed accommodation and restaurants (or } \\
\text { similar) }\end{array}$ & MA7 & \\
\hline $\begin{array}{l}\text { I think that the mountains have good services and facilities (attractions, mountain } \\
\text { sports facilities) }\end{array}$ & MA8 & \\
\hline I think that the mountains have convenient transportation & MA9 & \\
\hline
\end{tabular}


al. 2016; Chien 2017). Mountain foods have the potential to be very successful on the foodstuff market. Consumers associate peculiar organoleptic-sensorial characteristics to them due to the specific characteristics of the mountain environment, such as the absence of contamination (Bonadonna 2016).

Nowadays, mountain tourism supply should be conceived as an integrated product by developing alternative forms of tourism that exploit the wide range of destination attractions, including local gastronomy (Opačić \& Banda 2018). Food consumption can satisfy various needs and motivations, such as physiological, safety, social, esteem, and self-actualizing needs, thus playing a crucial role in shaping the overall tourist experience (Zuliani et al. 2018). Understanding tourist motivations to consume local food may contribute to develop a coherent tourism product, i.e. food and tourism-related services and marketing practice (Quan \& Wang 2004; Tikkanen 2007). Local food consumption may be either the main driver of the tourism experience or one aspect of a complex and multifaceted experience a destination might offer. From both perspectives, consumption of local food products plays a significant role in promoting at once the products and places of origin and other similar tourist destinations (Alderighi et al. 2016).

Ten items were selected to describe mountain food attractiveness, as shown in Table 2. Balmer \& Chen (2016) tested the "shop attractiveness" of a corporate heritage tourism brand since it may affect both shopping and wish to return, by taking into account the pleasure of (re)visiting a place with a long history. Choe \& Kim (2018) tested tourists' local food consumption and examined its effects on local food attitudes, food destination image, and behavioral intention. The "food destination image", "intention to recommend local food", and "intention to visit the destination for food tourism" constructs are described by variables that link the tourism destination to its ability to provide traditional food culture, diverse, and unique food, as well as variables that link the tourist experience to their willingness to repeat it and share it with other people. Lastly, Kim \& Eves (2012) provided a framework for assessing which motivations influence tourists' local food consumption. Their "cultural experience" and "interpersonal relation" constructs included several items, among which: tasting local food offers a unique opportunity to understand local cultures, it is a special experience, it is an opportunity to increase knowledge about different cultures, and so on.

\subsection{Mountain product label attitude (LA)}

Consumers' food attitudes represent a multidimensional and complex issue (Costell et al. 2010). They can be affected by brand equity: if brand awareness increases to a higher level and consumers hold stronger, more favorable and unique brand associations, their preferences and perceived values are positively affected (Rajh 2002; Vázquez et al. 2002; Wang 2015). A positive evaluation of the brand's central, distinctive, and enduring associations and characteristics increases its attractiveness (Elbedweihy et al. 2016).

Spears \& Singh (2004), quoting Mitchell \& Olson (1981), defined attitude toward the brand as an "individual's internal evaluation of the brand" and, in accordance with Fishbein \& Ajzen's (1975) formulation, stated that attitudes influence behavior through behavioral intentions. With respect to food choice and consumption, consumer behavior is based on a specific relationship of trust, and brand trust is positively associated with confidence in brand quality and safety, largely via trust in the food system

Table 2 Mountain food attractiveness construct. Items used in the questionnaire and sources for the standardized scales.

\begin{tabular}{l|l|l|}
\hline Items & Code & Source \\
\hline I think that the mountains, as a tourism destination, provide a rich food culture & MFA1 \\
\hline I think that the mountains, as a tourism destination, provide delicious food & MFA2 \\
I will say positive things about MP food to other people & MFA3 \\
\hline $\begin{array}{l}\text { I think that the mountains, as a tourism destination, provide traditional food } \\
\text { culture }\end{array}$ & MFA4 & BFalmer \& Chen 2016 \\
\hline I think that the mountains, as a tourism destination, provide diverse food & MFA6 Kim \& Eves 2012 \\
\hline I would like to (re)visit the mountains to explore different local foods & MFA7 \\
\hline I would like to travel to the mountains for food tourism & MFA8 \\
\hline I would like to come back to the mountains to enjoy MP food & MFA9 \\
\hline I think that the mountains, as a tourism destination, provide unique food & MFA10 \\
\hline I will recommend MP food to family and/or friends &
\end{tabular}


(Johnston \& Szabo 2011; Lassoued \& Hobbs 2015). In the case of organic food labeling, consumer attitudes toward organic foods and purchase intentions are affected by trust in the organic label, the nutritional value of organic food, environmental protection effects, as well as relational embeddedness in a channel (Liang 2016). Analyzing consumer attitudes towards private label food products, Lin et al. (2009) found that consumers are generally more concerned about quality than other characteristics, such as price. Nevertheless, if consumers are familiar with the brand, they have more confidence in evaluating product quality, reducing perceived risk and enhancing price consciousness.

Considering "brand attitude as the general appreciation of a brand by a consumer", following Mitchell \& Olson (1981), eighteen items of mountain product label attitude were selected, as shown in Table 3. Elbedweihy et al. (2016) and So et al. (2017) specifically focused on brand attractiveness and how it may affect consumer-brand identification. In analyzing the "brand attractiveness" construct, they considered the following items: I like what [Brand X] stands for/represents, I think that [Brand X] is an attractive brand, I like what [Brand X] represents/ embodies. Choe \& Kim (2018) investigated "emotional, health and taste/quality values" of local food consumption among the antecedents of the attitude toward local food, by considering fifteen items: food makes me feel happy and healthy, gives pleasure, good quality ingredients and appealing flavors, and so on.

\subsection{Purchase intention (PI)}

According to the Theory of Planned Behavior (TPB), specific behaviors are determined by an intention to perform them (Ajzen 1991; Wu \& Chen 2014; Zhu et al. 2013). TPB has been useful in predicting consumer intention and behavior (Kim \& Han 2010). A better food purchase intention can result in more food purchases (Zhu et al. 2013). However, there is a gap between consumers' intention and their actual purchase behavior in everyday decisions (Schäufele \& Hamm 2018). Recent literature indicated that purchase intention is affected by the context, as defined by a set of alternatives under consideration (Simonson \& Tversky 1992). Spears \& Singh (2004), while recognizing that the link between attitude and behavior is not always clear, described purchase intentions as "an individual's conscious plan to make an effort to purchase a brand". Moreover, Laroche \& Brisoux (1989) proposed a model of behavioral intentions that postulates that a consumer's intention to buy a specific brand is determined not only by the attitude toward that brand but also by other competing brands.

Purchase intention in this study is proposed and measured by ten selected items, as shown in Table 4 . Campbell \& Fairhurst (2016) analyzed the purchase intention for locally produced foods, considering the likelihood, certainty, probability and chance to buy such foods. In investigating private label (store brand, SB) purchase intention, Diallo (2012) evaluated the following four items: "the probability that I would

Table 3 Mountain Product (MP) label attitude construct. Items used in the questionnaire and sources for the standardized scales.

\begin{tabular}{|l|l|l|}
\hline Items & Code & Source \\
\hline I like what MP label represents/embodies & LA1 & LA2 \\
\hline I think that MP food is safe & LA3 \\
\hline I think that MP food is tasty & LA4 \\
\hline I think that eating MP food gives me pleasure & LA5 \\
\hline I think that MP food contains a variety of ingredients & LA6 \\
\hline I think that I am fascinated by MP food & LA7 \\
\hline I think that eating MP food makes me feel happy & LA8 & Choe \& Kim 2018 \\
\hline I think that MP food provides good nutrition & LA9 & LA10 \\
\hline I like what MP label stands for & LA11 & \\
\hline I think that MP food is hygienic & LA12 & LA13 \\
\hline I think that MP food makes me crave it & LA14 & LA15 \\
\hline I think that MP food contains good quality ingredients & LA16 \\
\hline MP label is an attractive label & LA17 \\
\hline I think that eating MP food changes my mood positively & LA18 \\
\hline I think that MP food provides a high standard of quality & \\
\hline I think that MP food makes me healthy & \\
\hline I think that eating MP food makes me feel excited & I think that MP food provides appealing flavors & \\
\hline
\end{tabular}


consider buying SBs is high", "I would purchase SBs next time", "I would consider buying SBs", and "there is a strong likelihood that I will buy SBs". Finally, Zafar \& Rafique (2012), studying both the product and the store, investigated the purchase intention considering the likelihood to purchase the product, try the product if seen in a store, and actively seek out the product in a store.

\subsection{Proposed model}

Our study proposes a research model of the relationships between the four latent constructs, positing a hierarchy in which mountain attractiveness and mountain food attractiveness are determinants of the attitude towards the mountain product label, which affects the purchase intention. The proposed hierarchy is analogous to other value-attitudebehavior hierarchies identified in the literature (e.g., Homer \& Kahle 1988; Thøgersen \& GrunertBeckmann 1997), following a belief-based approach adapted from Fishbein's multiattribute attitude model (Fishbein 1963) and further extensions of this framework, such as the Theory of Planned Behavior
(Ajzen 1985; Ajzen \& Fishbein 1980).

Specifically, the following hypotheses are proposed and tested (Fig. 1):

H1: Mountain attractiveness (MA) has a positive impact on mountain product label attitude (LA).

H2: Mountain food attractiveness (MFA) has a positive impact on mountain product label attitude (LA).

H3: Mountain product label attitude (LA) has a positive impact on purchase intentions (PI) toward mountain food products.

\section{Methodology}

The research was structured in three main tasks: questionnaire planning, data collection and data analysis.

The questionnaire consisted of two sections. The first section aimed at exploring the respondent's sociodemographic characteristics such as gender, age, education level, family income and province of residence. Two specific questions were also included to investigate whether and why respondents know

Table 4 Purchase intention construct. Items used in the questionnaire and sources for the standardized scales.

\begin{tabular}{|c|c|c|}
\hline Items & Code & Source \\
\hline The probability that I would consider buying MP food is high & PI1 & \multirow{10}{*}{$\begin{array}{l}\text { Campbell \& Fairhurst } 2016 \\
\text { Diallo } 2012 \\
\text { Zafar \& Rafique } 2012\end{array}$} \\
\hline I would purchase MP food next time & PI2 & \\
\hline $\begin{array}{l}\text { There is a strong likelihood that I will try this product if seen in a Farm shop / } \\
\text { Mountain hut }\end{array}$ & PI3 & \\
\hline There is a strong likelihood that I will try this product if seen in a Supermarket & $\mathrm{PI} 4$ & \\
\hline $\begin{array}{l}\text { There is a strong likelihood that I will try this product if seen in Food store } \\
\text { specialties }\end{array}$ & PI5 & \\
\hline I would consider buying MP food & PI6 & \\
\hline There is a strong likelihood that I will buy MP food & $\mathrm{PI} 7$ & \\
\hline $\begin{array}{l}\text { There is a strong likelihood that I will seek out this product in a Farm shop / } \\
\text { Mountain hut }\end{array}$ & PI8 & \\
\hline There is a strong likelihood that I will seek out this product in a Supermarket & PI9 & \\
\hline $\begin{array}{l}\text { There is a strong likelihood that I will seek out this product in Food store } \\
\text { specialties }\end{array}$ & PI10 & \\
\hline
\end{tabular}

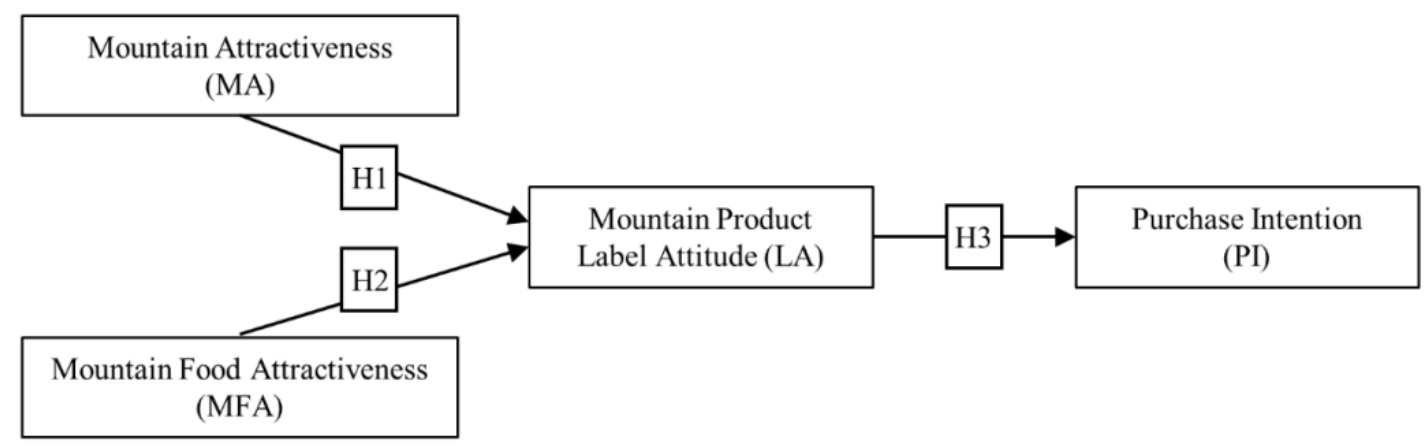

Fig. 1 Proposed model of the relationships among the four latent constructs. 
mountains (because they live, work, and/or for tourism reasons) and if they know mountain foodstuffs. The second section of the questionnaire included 47 items: nine on "mountain attractiveness", ten on "mountain food attractiveness", 18 on "Mountain product label attitude", and ten on "purchase intention" (Tables 1, 2, 3, 4). Each item was explored using a 5-point Likert-like scale, ranging from 1 (strongly disagree) to 5 (strongly agree). Despite adverse criticism, Likert and Likert-like scales are often chosen in attitude scale construction and measurement for their reliability and ease of use (Allen and Kenney 1946).

Data collection was managed by an external specialized company, Demetra opinioni.net srl. Given the increasing popularity of the Internet and the profitable use of an online access panel, Data were collected through a CAWI (Computer Assisted Web Interview) survey. Web-based questionnaires allow for complexity but may appear simple and attractive. An online access panel is a pool of people who have agreed to repeatedly take part in web surveys (Gritz et al. 2002). Online panels are an important, if not the dominant, form of reactive web-based research in the medium term (Couper 2000). A panel can be used as a sampling source for thematically and methodologically diverse studies. In contrast to ad hoc recruitment, online panels reduce the cost associated with locating appropriate respondents and ensure their immediate availability, along with additional benefits such as easy identification of key sample segments, increased response rate, augmented response quality, shorter field times and ethical advantages (Gritz et al. 2002). In addition, there are no data entry costs. In order to minimize the disadvantages of the CAWI method, a pilot study was previously conducted.

Participation in the survey was limited to people who live in Friuli Venezia Giulia, Italy's most northeastern region. The probabilistic sample extracted from a proprietary panel was stratified by geographical location, gender and age to reflect sociodemographic characteristics of the population. The peculiar features and characteristics of the study area make it specifically interesting and well-suited for the research design and scope. The region extends from the Dolomites and the Alps on the north to the Upper Adriatic Sea on the south, with mountains covering $43 \%$ of the region's total area $\left(7,858 \mathrm{~km}^{2}\right)$. Two of the four administrative areas of the region,
Udine and Pordenone, stretch from the mountains to the southern flatlands; the territory of the other two provinces is mainly hilly (Gorizia) and coastal (Trieste). Given the specific geography of the region, the mountain economy is typically rooted in the north and produces several traditional food products. Nevertheless, the inner diversity of the territory and the distance between mountain and coastal areas result in different degrees of knowledge, understanding, interpretation of, and attachment to mountains and the mountain economy.

As the questionnaire was compiled employing a set of well-known and fully investigated scales, the analysis focused on the evaluation of the scales' reliability in this specific context. The analysis was developed using the Cronbach's Alpha index as a first descriptive tool, and the Confirmative Factor Analysis (CFA) was used to build the constructs summary measures. The structure defined in sub-sections $2.1-$ 2.4 was tested and the results were reported in subsection 4.2.

The estimated constructs and the other information collected in the survey were used to analyze the causal relationship between the constructs defined in sub-section 2.5 and the influence of the sociodemographic variables on them. Results of these analyses are given in sub-sections 4.3 and 4.4, respectively.

Finally, the influence of each item in the explanation of the purchase intentions construct was investigated considering the linear model specification

$\mathrm{PI}_{\mathrm{i}}=\alpha+\sum_{\mathrm{k}=1}^{9} \beta_{\mathrm{k}} \mathrm{MA}_{\mathrm{ki}}+\sum_{\mathrm{j}=1}^{10} \theta_{\mathrm{j}} \mathrm{MF}_{\mathrm{ji}}+\sum_{\mathrm{l}=1}^{18} \gamma_{\mathrm{l}} \mathrm{LA}_{\mathrm{li}}+\epsilon_{\mathrm{i}}$

where each summation correspond to one of the considered scales and the error term was supposed to be Gaussian with null mean and constant variance $\sigma_{\epsilon}^{2}$. This kind of model suffers two kind of shortcuts. Namely, the esplicative variables were highly correlated and the model was overparameterized (the model included 38 regression parameters including the intercept). For this reasons the model estimation had been performed considering also two well-known regularization methods, i.e. Ridge and Least Absolute Shrinkage and Selection Operator (LASSO) regressions. These two methodologies are based on the penalization of the classical OLS loss function obtained as follows.

$$
\mathrm{L}_{\mathrm{pen}}(\delta)=\sum_{\mathrm{i}=1}^{\mathrm{n}}\left(\mathrm{y}_{\mathrm{i}}-\mathrm{x}_{\mathrm{i}}^{\prime} \delta\right)^{2}+\lambda \sum_{\mathrm{j}=1}^{\mathrm{m}}\left|\delta_{\mathrm{j}}\right|^{\mathrm{k}},
$$


where $\delta$ is the full regression parameters vector, $\lambda$ is the penalization parameter ( $\lambda=0$ brings to OLS estimates) and $k$ is 1 for LASSO and 2 for Ridge regression, respectively. From the empirical point of view, for large values of $\lambda$ the regression parameters can be exactly zeroed in the LASSO penalization case, while the Ridge regression solution causes the shrinkage of the parameters. Results of these analyses are summarized in sub-section 4.5 .

All the empirical analyses were developed in $\mathrm{R}(\mathrm{R}$ Core Team 2021) using core functions and three additional libraries. In particular, we used the "psych" library (Revelle 2019) to study the reliability of the four multi-items scales and determine the behavior of the single items in them. The "lavaan" library (Rosseel, 2012) was used for the CFA and for the estimation of the Structural Equation Model (SEM) underlying the regression analysis developed to study the model and working hypotheses. Finally, the "glmnet" library (Friedman et al. 2010) was used to study the relevance of the items on the studied constructs.

\section{Results}

\subsection{Sample characteristics}

The characteristics of the sample are summarized in Table 5. The total sample size was 310. It included respondents from all four provinces of Friuli Venezia Giulia, a region in north-eastern Italy. Most of them were from the provinces of Trieste (39.4\% of the units) and Udine (23.4\%) and lived in small municipalities (31.6\%). The sample included $57.1 \%$ of females and $42.9 \%$ of males. All age classes were adequately represented. The largest number of respondents falls into the middle age classes, that are 35-44 and 45-54 years old, i.e. $27.7 \%$ and $20.6 \%$, respectively. Most respondents (82.6\%) held at least a high school diploma. The size of the subsamples defined on the basis of income classes was quite uneven. Most of the respondents were people with low (less than 1,500 euro per month) or mid-low (between 1,500 and 3,000 euro) income level (24.8\% and $55.5 \%$ respectively). As far as mountain knowledge was concerned, a few people in the sample (7.1\%) declared knowledge of mountains because they live in mountain municipalities, 21.9\% because they work in such areas, and most of them (71.0\%) because they go to mountains for tourism. Finally, $23.9 \%$ of respondents declared to know mountain food products.

Table 5 Sample composition by characteristics of the statistical units $(N=310)$.

\begin{tabular}{|c|c|c|}
\hline Characteristics & Classes & $N$ \\
\hline \multirow{4}{*}{$\begin{array}{l}\text { Province of } \\
\text { residence }\end{array}$} & Trieste & 122 \\
\hline & Udine & 91 \\
\hline & Pordenone & 57 \\
\hline & Gorizia & 40 \\
\hline \multirow{4}{*}{$\begin{array}{l}\text { Municipality } \\
\text { size } \\
(N \\
\text { inhabitants) }\end{array}$} & $<10,000$ & 98 \\
\hline & $10,000-29,999$ & 65 \\
\hline & $30,000-100,000$ & 66 \\
\hline & $>100,000$ & 81 \\
\hline \multirow{2}{*}{ Gender } & Female & 177 \\
\hline & Male & 133 \\
\hline \multirow{6}{*}{ Age (years) } & $18-24$ & 35 \\
\hline & $25-34$ & 49 \\
\hline & $35-44$ & 86 \\
\hline & $45-54$ & 64 \\
\hline & $55-64$ & 40 \\
\hline & $>64$ & 36 \\
\hline \multirow{4}{*}{$\begin{array}{l}\text { Educational } \\
\text { level }\end{array}$} & Elementary school & 4 \\
\hline & Lower secondary school & 50 \\
\hline & Higher secondary school & 167 \\
\hline & Degree & 89 \\
\hline \multirow{5}{*}{$\begin{array}{l}\text { Income level } \\
€ \text { (euro) }\end{array}$} & $<1,500$ & 77 \\
\hline & $1,500-3,000$ & 172 \\
\hline & $3,001-5,000$ & 54 \\
\hline & $5,001-10,000$ & 2 \\
\hline & $>10,000$ & 5 \\
\hline \multirow{3}{*}{$\begin{array}{l}\text { Mountain } \\
\text { knowledge }\end{array}$} & My home & 22 \\
\hline & Work & 68 \\
\hline & Tourism & 220 \\
\hline \multirow{2}{*}{$\begin{array}{l}\text { Mountain food } \\
\text { knowledge }\end{array}$} & Yes & 74 \\
\hline & No & 236 \\
\hline
\end{tabular}

\subsection{Analysis of the constructs: reliability and confirmative factor analyses}

The analysis of the reliability of the constructs confirmed the internal validity of the scales. All the items can be included in the measurement of the latent dimensions. Cronbach's alpha, item whole correlation (corrected for item overlap and scale reliability), scale and position summary statistics were computed for each item in the scales. The correlation between items and the total score showed that none of the items presented alarming summary statistics. The only item not fully integrated into the specific scale was MA9 ("I think that the mountains have convenient transportation") used to study the "mountain attractiveness" construct, which presented a correlation equal to 0.57. The Cronbach's Alpha values were all over 0.9 , confirming the evidence obtained with the detailed correlation analysis. In 
particular, the values were $0.97,0.94,0.91$ and 0.96 for label attractiveness, purchase intention, mountain attractiveness and mountain food attractiveness, respectively. No relevant change was observed when excluding specific items from the scales.

As mentioned, the validity of the full measurement tool was also explored, employing CFA. This approach allowed the constructs to be studied jointly and can also be used to explore the relationship existing between the four constructs. The CFA results can be analyzed after considering a discussion on the model fit. In general, we can observe that the Comparative Fit Index (CFI) and the Tuker-Lewis Index (TLI) are 0.848 and 0.840 , respectively, and they are both just below the conventional threshold for the two criteria (0.90). This result can be considered acceptable given the sample size. Another fit measure was the Root Mean Square Error of Approximation (RMSEA) which presented a value of 0.083 , indicating an acceptable model fit. In general, the model fit is good when this summary statistic is lower than 0.05, but again in the present framework, the results can be considered acceptable. Finally, the Standardized Root Mean Square Residual (SRMR) was 0.047, indicating a good model fit. All these measures were developed for structural equation models where variables are normally distributed, so they do not perfectly fit the aim of the present study, as in a generic marketing study, where items correspond to Likert scale measures. For this reason, we can consider the results as acceptable. The estimated correlation between constructs is quite high, suggesting a relevant relationship between the constructs (Table 6).

Table 6 Confirmative Factor Analysis results: correlations between constructs.

\begin{tabular}{|l|l|l|l|l|}
\hline & MA & MFA & LA & PI \\
\hline MA & 1.00 & - & - & - \\
\hline MFA & 0.89 & 1.00 & - & - \\
\hline LA & 0.77 & 0.78 & 1.00 & - \\
\hline PI & 0.83 & 0.88 & 0.79 & 1.00 \\
\hline
\end{tabular}

Notes: MA, Mountain attractiveness; MFA, Mountain food attractiveness; LA, Mountain Product label attitude; PI, Purchase intention.

All the considered items presented valuable loadings. The lowest value corresponds to the last item of the mountain attractiveness construct, as the preliminary analysis also suggested. The full results of the CFA analysis are omitted because the analysis of the factor loading is redundant when considering the path analysis developed in the following section.

\subsection{Causal relationship analysis}

The study of the causal relationship between the estimated constructs, hypothesized in Section 3 and illustrated in Figure 1, can be tackled considering the specification of an SEM where the latent variable identifying the purchase intentions (PI) was directly related to the label attitude (LA), and the other two constructs (mountain attractiveness - MA and mountain food attractiveness - MFA) caused the LA. The SEM approach was adopted to study the causal relationship between constructs. The factor loadings obtained at this step were entirely comparable with those of the simple CFA analysis. The model goodness of fit indexes was also similar and sometimes better than those reported in Section 4.2.

Table 7 shows the results of the two regressions involved in the analysis of the effects of the attractiveness constructs on purchase intentions. All the coefficients, except the one associated with the direct effect of MA on PI, are significantly different from zero. The measure of LA is significantly affected by the MA and MFA. The estimated direct effects are all positive, and the size of their coefficients suggests that MFA was the most relevant factor in determining purchase intentions. The direct effect of brand attractiveness is also significant. Given the structure of the hypothesized relationships, we are also able to summarize these regressions extracting the indirect and total effects for the two constructs involved in the LA regression. Taking these results in an SEM framework, we can also proceed with inference on these results. The reported $\mathrm{R}^{2}$ suggested an excellent model fit regarding the regression component of the analysis. The last part of Table 8 reports this kind of analysis. All the estimated effects are significantly different from zero, and the reported results suggest that the total effect connected with MFA was more significant than that of the MA. Even if the direct effect of MA on PI is not significantly different from zero, both the total and indirect effects are statistically relevant. Due to the standardized nature of the involved measures, the coefficients' size can be directly considered for this comparison. A graphical representation of the estimated paths is shown in Fig. 2.

The scores of the four factors are summarized conditionally to the observed contextual variables (sample characteristics). Table 8 shows the results of 
Table 7 Results of Structural Equation Model. The estimated parameter for the constructs' regression models.

\begin{tabular}{ll|l|l|l|l|} 
Regressions & & Estimate & Std.Err & z-value & $\mathrm{P}(>|\mathrm{z}|)$ \\
\hline \multirow{5}{*}{ PI Model } & MA (c1) & 0.141 & 0.101 & 1.390 & 0.165 \\
& MFA (c2) & 0.596 & 0.095 & 6.300 & $<0.001^{* * *}$ \\
& LA (b) & 0.237 & 0.053 & 4.522 & $<0.001^{* * *}$ \\
& $R^{2}$ & 0.806 & & & \\
LA Model & MA (a1) & 0.434 & 0.128 & 3.382 & $0.001^{* *}$ \\
& MFA (a2) & 0.490 & 0.113 & 4.342 & $<0.001^{* * *}$ \\
\hline Covariances & $R^{2}$ & 0.638 & & & \\
\hline \multirow{5}{*}{ Defined Parameters } & MA - MFA & 0.490 & 0.052 & 9.371 & $<0.001^{* * *}$ \\
& Indirect MA & 0.103 & 0.038 & 2.697 & $0.007^{* *}$ \\
& Indirect MFA & 0.116 & 0.035 & 3.292 & $0.001^{* *}$ \\
& Total MA & 0.244 & 0.104 & 2.343 & $0.019^{*}$ \\
& Total MFA & 0.712 & 0.098 & 7.256 & $<0.001^{* * *}$
\end{tabular}

Note: "**** means that $p$-value is lower than 0.001, “**” means that p-value is between 0.001 and 0.01 , “*” means that p-value is between 0.01 and 0.05 and "." means that the $p$-value is between 0.05 and 0.1 and, finally, no symbol is reported for $p$-values larger than o.1. MA, Mountain attractiveness; MFA, Mountain food attractiveness; LA, Mountain Product label attitude; PI, Purchase intention.

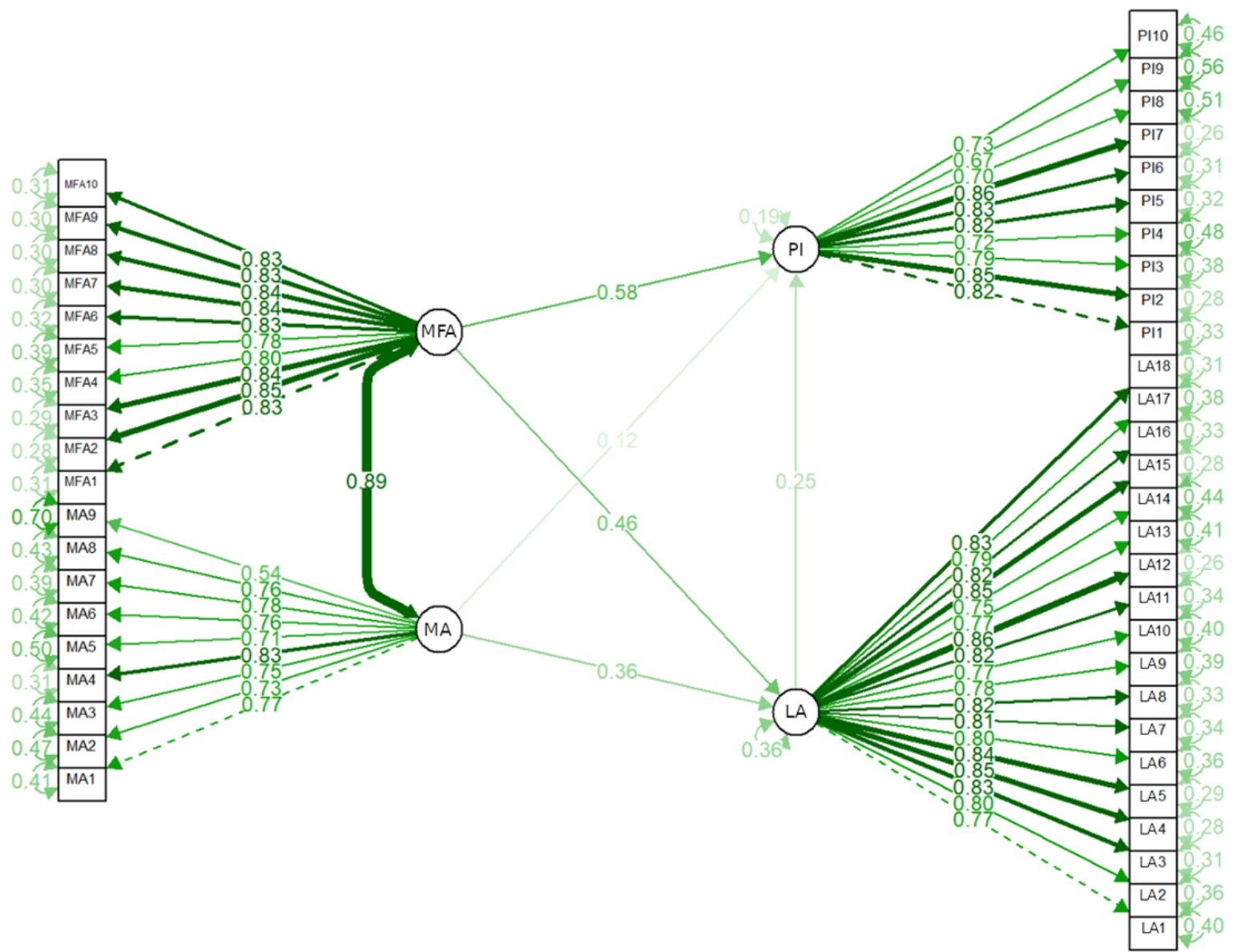

Fig. 2 Path analysis for the identification of the significant relationships among constructs.

the mean comparison tests (t-tests or ANOVA tests) developed for each factor and each contextual variable. As a result, a small part of the conducted tests shows statistically relevant differences (at a significance level of 0.05). MA and MFA scores are affected by the province of residence, and age class affects the LA scores. The mountain knowledge and the mountain food knowledge factors significantly impact the mean values of the four scores. In particular, the mountain food knowledge shows a positive significative effect on the factors scores. The reason why people know the mountains affects the scores level. All factors 
Table 8 Analysis of the relationship between constructs and observed contextual variables.

\begin{tabular}{|c|c|c|c|c|c|}
\hline Variables & Classes & PI & LA & MA & MFA \\
\hline \multirow{5}{*}{$\begin{array}{l}\text { Province of } \\
\text { residence }\end{array}$} & Gorizia & 0.126 & 0.145 & 0.199 & 0.083 \\
\hline & Pordenone & 0.268 & 0.170 & 0.246 & 0.303 \\
\hline & Trieste & -0.080 & -0.004 & -0.044 & -0.088 \\
\hline & Udine & -0.107 & -0.124 & -0.147 & -0.103 \\
\hline & $p$-value & 0.071 & 0.215 & 0.039* & 0.050 * \\
\hline \multirow{5}{*}{ Municipality size } & $0-10000$ & 0.083 & 0.041 & 0.031 & 0.079 \\
\hline & $10001-30000$ & -0.041 & 0.042 & 0.012 & -0.046 \\
\hline & $30001-100000$ & -0.057 & -0.020 & -0.066 & -0.051 \\
\hline & $100001-250000$ & -0.016 & -0.093 & 0.004 & -0.011 \\
\hline & $p$-value & 0.784 & 0.818 & 0.938 & 0.803 \\
\hline \multirow{3}{*}{ Gender } & Female & 0.051 & 0.036 & 0.023 & 0.038 \\
\hline & Male & -0.068 & -0.048 & -0.030 & -0.051 \\
\hline & $p$-value & 0.292 & 0.463 & 0.635 & 0.433 \\
\hline \multirow{7}{*}{ Age-class } & $18-24$ & -0.397 & -0.448 & -0.252 & -0.253 \\
\hline & $25-34$ & -0.097 & -0.226 & -0.133 & -0.122 \\
\hline & $35-44$ & 0.219 & 0.151 & 0.134 & 0.197 \\
\hline & $45-54$ & -0.022 & 0.108 & 0.003 & -0.017 \\
\hline & $55-64$ & 0.070 & 0.124 & 0.028 & 0.029 \\
\hline & $64+$ & -0.044 & 0.052 & 0.070 & -0.059 \\
\hline & $p$-value & $0.053^{\circ}$ & $0.020 *$ & 0.401 & 0.245 \\
\hline \multirow{4}{*}{ Educational level } & LowEdLev & 0.114 & 0.066 & 0.171 & 0.145 \\
\hline & AvEdLev & 0.027 & 0.023 & 0.032 & 0.044 \\
\hline & HighEdLev & -0.119 & -0.083 & -0.163 & -0.170 \\
\hline & $p$-value & 0.336 & 0.619 & 0.113 & 0.126 \\
\hline \multirow{4}{*}{ Income level } & LowInc & -0.243 & -0.218 & -0.146 & -0.247 \\
\hline & AvInc & 0.116 & 0.079 & 0.061 & 0.085 \\
\hline & HighInc & -0.020 & 0.052 & 0.014 & 0.072 \\
\hline & $p$-value & $0.027^{*}$ & $0.081 \cdot$ & 0.298 & $0.039 *$ \\
\hline \multirow{4}{*}{$\begin{array}{l}\text { Mountain } \\
\text { knowledge }\end{array}$} & Work & -0.429 & -0.478 & -0.392 & -0.391 \\
\hline & Tourism & 0.110 & 0.140 & 0.127 & 0.102 \\
\hline & My Home & 0.225 & 0.073 & -0.057 & 0.191 \\
\hline & $p$-value & $<0.001 * * *$ & $<0.001 * * *$ & $<0.001 * * *$ & $0.001 * *$ \\
\hline \multirow{3}{*}{$\begin{array}{l}\text { Mountain food } \\
\text { knowledge }\end{array}$} & No & -0.111 & -0.130 & -0.083 & -0.076 \\
\hline & Yes & 0.353 & 0.413 & 0.264 & 0.241 \\
\hline & $p$-value & $<0.001 * * *$ & $<0.001 * * *$ & $0.007^{* *}$ & 0.016 * \\
\hline
\end{tabular}

Note: “***” means that p-value is lower than 0.001, “**” means that p-value is between 0.001 and 0.01 , “*” means that p-value is between 0.01 and 0.05 and "." means that the p-value is between 0.05 and 0.1 and, finally, no symbol is reported for p-values larger than o.1. MA, Mountain attractiveness; MFA, Mountain food attractiveness; LA, Mountain Product label attitude; PI, Purchase intention.

present negative average values for people working in the mountains, while factors are presenting positive means for people living in or visiting the mountains.

\subsection{Effect of some contextual variables}

The survey included a certain amount of contextual information on the respondents (Table 5). On the basis of the results reported in the previous sub-section, the effect of these variables was measured by also considering them in the SEM. The regression analysis was conducted using a stepwise procedure for the selection of the explicative variables. The preliminary analysis conducted to examine the behavior of the four constructs conditionally to the contextual variables is reported in the previous section. The results of this analysis guided the following data transformation steps. First of all, some levels of the considered variables were aggregated. In particular, the income level was reduced to three classes aggregating the three highest original levels, and the education level was reduced to three classes aggregating the two lowest original levels. These simplifications were connected to the very low sample size of some classes initially considered in the data collection and to the substantial homogeneity between the aggregated levels.

The results reported in the Appendix show that 
the variables presenting significant effects on the estimated constructs are age class, income level and the province of residence. The province affects the level of MA and MFA constructs (with observed significance levels of 0.04 and 0.05 , respectively). The age class is significantly related to the PI and LA ( $p$ value 0.05 and 0.02 , respectively). Finally, the income level affects the MFA and purchase intentions ( $p$ value 0.04 and 0.03 , respectively). The factors identifying the knowledge of the mountain and mountain products show relevant effects on the whole set of constructs. All the p-values except the one regarding the relationship between mountain product knowledge and MFA are lower than 0.01. These results, along with some other empirical evidence obtained from the model estimation, guide the selection of the explicative variables included in the final model specification. In particular, the selection of the explicative variables is based on the Akaike and Bayesian information criteria (AIC and BIC). The contribution of the covariates is evaluated with a stepwise approach. In each step, they are considered for addition to or subtraction from the set of selected variables.

The final model specification does not include some specific relationships recognized in the preliminary analysis. In particular, the MFA specific regression was excluded from the model because the estimation results show that the contribution of this model component is negligible. Moreover, the relationship between income and LA was not significant. The estimation results for the final model specification are reported in Table 9, following the outline of Table 8 . The comparison of the two results shows that the inclusion of the control variables (additional explicative variables) does not have noticeable effects on the parameters included in both specifications. The most relevant difference is that the direct effect of MA on PI is significant in the model with exogenous variables.

Results in Table 9 show the effect of control variables on the studied constructs. For the PI regression model of the age class factor the effect is significant. The benchmark level for age class is 18-24. All the estimated coefficients are positive, meaning that the purchase intention in all the considered classes is higher than the one observed in the reference class. The benchmark was set to "average income" (1,500-3,000 euro) for income level. In the PI model, both low and high income show negative coefficients, meaning that the purchase intention is lower in these two classes. The coefficient of high income is barely significant (at a level of 10\%). Lastly, mountain products knowledge positively affects purchase intentions (p-value 0.03).

In the LA regression model, the estimated coefficients of the age class factor show that label attractiveness changes with age. With respect to the benchmark category (less than 25), the class-specific coefficients are all positive and increasing in the first three classes and substantially stable in the last three (estimated coefficients are $0.102,0.238,0.368,0.369$, and 0.336). Looking at the basic contrasts defined in the model, we cannot directly infer the incremental effect of the single age classes, but the coefficients (at least for the first three levels) show increasing values. The estimated coefficients for the last three classes are very similar, meaning no relevant differences exist between them. Mountain product knowledge shows a significant and positive effect on label attractiveness. The mountain knowledge factor is also included in the regression models. The reference class here is "mountain is my home". As can be noted, the estimated coefficient for the tourism dummy is significant and positive, while the coefficient for the work dummy is not significantly different from zero.

The last regression summarized in Table 9 regards the mountain attractiveness construct. The estimation results show that the relevant variables identify the province of residence, the dummy for mountain product knowledge and the mountain knowledge factor. The estimation results showed that people living in Udine presented an average MA value significantly lower than those living in Gorizia (representing the benchmark level for the factor). The product knowledge presents a positive effect on the construct. Knowing the mountain for work has no significant effect on mountain attractiveness, while the tourism dummy variable presents a significant and positive effect.

Analysis of the total and indirect effects shows that both are significant and positive, confirming the results of the PI regression that can be interpreted as the analysis of direct effects.

\subsection{How much the single items explain the PI construct}

The analyses presented in the previous sections show that all the items adopted for the measurement 
Table 9 Results of the regression models with exogenous variables. The estimated parameter for the constructs' regression models including the exogenous contextual variables.

\begin{tabular}{|c|c|c|c|c|c|}
\hline \multicolumn{2}{|l|}{ Regressions } & Estimate & Std.Err & z-value & $\mathrm{P}(>|\mathrm{z}|)$ \\
\hline \multirow{12}{*}{ PI Model } & MA (c1) & 0.208 & 0.070 & 2.950 & $0.003^{* *}$ \\
\hline & MFA (c2) & 0.569 & 0.070 & 8.099 & $<0.001^{* * *}$ \\
\hline & LA (b) & 0.200 & 0.054 & 3.732 & $<0.001^{* * *}$ \\
\hline & 25-34 years & 0.184 & 0.092 & 1.997 & $0.046 *$ \\
\hline & $35-44$ years & 0.197 & 0.084 & 2.338 & $0.019^{*}$ \\
\hline & 45-54 years & 0.108 & 0.086 & 1.224 & 0.221 \\
\hline & 55-64 years & 0.182 & 0.097 & 1.878 & 0.060 \\
\hline & $>64$ years & 0.100 & 0.099 & 1.016 & 0.310 \\
\hline & $<1,500$ euro & -0.079 & 0.058 & -1.351 & 0.177 \\
\hline & $>3,000$ euro & -0.110 & 0.062 & -1.784 & 0.074 . \\
\hline & Mountain food knowledge & 0.123 & 0.057 & 2.144 & 0.032 * \\
\hline & $\mathrm{R}^{2}$ & 0.747 & & & \\
\hline \multirow{11}{*}{ LA Model } & MA (a1) & 0.356 & 0.088 & 4.715 & $<0.001^{* * *}$ \\
\hline & MFA (a2) & 0.543 & 0.078 & 6.764 & $<0.001^{* * *}$ \\
\hline & 25-34 years & 0.102 & 0.112 & 0.909 & 0.363 \\
\hline & $35-44$ years & 0.238 & 0.104 & 2.303 & $0.021 *$ \\
\hline & $45-54$ years & 0.368 & 0.108 & 3.400 & $0.001 * *$ \\
\hline & $55-64$ years & 0.369 & 0.119 & 3.101 & $0.002 * *$ \\
\hline & $>64$ years & 0.336 & 0.124 & 2.714 & $0.007^{* *}$ \\
\hline & Mountain food knowledge & 0.233 & 0.070 & 3.304 & $0.001 * *$ \\
\hline & Mountain knowledge - Work & 0.198 & 0.173 & 1.144 & 0.253 \\
\hline & Mountain knowledge - Tourism & 0.185 & 0.072 & 2.581 & $0.010 *$ \\
\hline & $\mathrm{R}^{2}$ & 0.562 & & & \\
\hline \multirow{7}{*}{ MA Model } & Udine & -0.301 & 0.126 & -2.391 & $0.017^{*}$ \\
\hline & Trieste & -0.206 & 0.131 & -1.577 & 0.115 \\
\hline & Pordenone & -0.049 & 0.142 & -0.346 & 0.729 \\
\hline & Mountain food knowledge & 0.160 & 0.094 & 1.705 & 0.088 \\
\hline & Mountain knowledge - Work & -0.342 & 0.227 & -1.506 & 0.132 \\
\hline & Mountain knowledge - Tourism & 0.269 & 0.091 & 2.945 & $0.003^{* *}$ \\
\hline & $\mathrm{R}^{2}$ & 0.094 & & & \\
\hline \multirow{4}{*}{$\begin{array}{l}\text { Defined } \\
\text { Parameters }\end{array}$} & Indirect MA & 0.071 & 0.026 & 2.794 & $0.005^{* *}$ \\
\hline & Indirect MFA & 0.109 & 0.032 & 3.442 & $0.001^{* *}$ \\
\hline & Total MA & 0.279 & 0.071 & 3.957 & $<0.001 * * *$ \\
\hline & Total MFA & 0.677 & 0.070 & 9.744 & $<0.001^{* * *}$ \\
\hline
\end{tabular}

Note: “***” means that $p$-value is lower than 0.001 , “**” means that $p$-value is between 0.001 and 0.01 , “*” means that $p$-value is between 0.01 and 0.05 and "." means that the $p$-value is between 0.05 and 0.1 and, finally, no symbol is reported for $p$-values larger than 0.1 .

of latent constructs are relevant. In addition, the study of the relationship between latent constructs revealed the significance of direct and indirect effects of the LA, MA and MFA constructs on purchase intention. The path model interpretation can then be integrated considering a further analysis regarding the effects of the single items on purchase intention.

With this aim, regularization methods can be used to support the study of the relationship between the latent constructs. Both Ridge and LASSO regression are adopted in the analysis. These approaches focus on the predictive capability of the regression, and, for this reason, we can consider them as further evidence on the relevance of the estimated effects. Purchase intentions are regressed over the full set of items composing the LA, MA and MFA constructs. The aim of this analysis was the identification of items that can be considered as most relevant in the explanation of purchase intention. The analyses were developed in $\mathrm{R}$ using the "glmnet library" for Ridge and LASSO regressions.

The regularization results are obtained considering a standard approach for the tuning of the penalization parameters. The complete sample has been equally split between train and test set, and the optimal values for penalization have been determined by the cross-validation approach. As expected, the results of the different regularization methods are mostly coherent. LASSO results show that 20 coefficients out of 37 can be considered null applying the regularization. Their predictive power is negligible, so the complexity of the model can be reduced. A hint in this direction also came from the reliability analysis. Cronbach's alpha was not severely affected by the 
exclusion of items from the scales, meaning that the contribution of the single items to the latent constructs was mostly overlapped. The regularised regression analysis, reported in Tables 10 and 11, can be used to identify which items are more critical in determining purchase intention value. In particular, coherently with the regression presented in Tables 6 and 9, items from all the scales are considered relevant. As reported in Table 10, the LASSO regression identified 17 items as relevant, i.e. five, six, and six relevant for the MA, LA, and MFA constructs, respectively. The results of Ridge and linear model estimation are given in Table 11 for the items presenting a null coefficient in the LASSO regression.

\section{Discussion}

The EU regulation on the Mountain product label is quite recent, at least in its application. Existing literature on this topic has mainly dealt with production-related aspects, while information on consumer behavior is still lacking. Indeed, advances in knowledge on the attitudes of consumers towards this new label, as well as their purchase intentions, is essential to relate marketing communication to consumers' needs and preferences (Baritaux et al. 2011), support mountain development strategies and promote the adoption of co-marketing and cobranding actions for products and the territory.

The results of our study primarily show that all the 47 selected items are suitable to describe the four latent dimensions; moreover, the postulated relationship between the constructs is relevant and confirmed. Besides the positive effect of mountain attractiveness and mountain food attractiveness (MA and MFA) on the attitude towards the mountain product label (LA), our analysis confirms the direct relationship between label attitude (LA) and purchase intentions (PI). Moreover, the total and indirect effects of MA and MFA on PI are statistically significant as well. Hence, the actual experience of mountain areas and their traditional products is enhanced by their specific features (social and environmental context, landscapes, culinary traditions, food quality), and this acts as a potential motivation to repeat the experience These results are in line with existing literature on mountain food and

Table 10 Purchase intention (PI) as a function of the Mountain attractiveness (MA), Mountain food attractiveness (MFA) and Mountain Product label attitude (LA) items. Regression coefficients corresponding to non-null values in the Lasso regression.

\begin{tabular}{|c|c|c|c|c|}
\hline Code & Items & LM Coef & Ridge Coef & LASSO Coef \\
\hline LA11 & I think that MP food makes me crave it & 0.2445 & 0.0795 & 0.1563 \\
\hline MFA10 & I will recommend MP food to family and/or friends & 0.1068 & 0.0730 & 0.1465 \\
\hline MA4 & $\begin{array}{l}\text { I think that the mountains have unique local specialties } \\
\text { (good food) and souvenirs }\end{array}$ & 0.1500 & 0.0611 & 0.1287 \\
\hline MFA8 & $\begin{array}{l}\text { I would like to come back to the mountains to enjoy MP } \\
\text { food }\end{array}$ & 0.1705 & 0.0646 & 0.0983 \\
\hline LA1 & I like what MP label represents/embodies & 0.0853 & 0.0511 & 0.0912 \\
\hline MA5 & $\begin{array}{l}\text { I think that the mountains have beautiful/attractive } \\
\text { scenery }\end{array}$ & 0.1167 & 0.0584 & 0.0797 \\
\hline LA16 & I think that MP food makes me healthy & 0.1593 & 0.0453 & 0.0764 \\
\hline MFA3 & I will say positive things about MP food to other people & 0.1531 & 0.0654 & 0.0749 \\
\hline MFA9 & $\begin{array}{l}\text { I think that the mountains, as a tourism destination, } \\
\text { provide unique food }\end{array}$ & 0.0483 & 0.0559 & 0.0654 \\
\hline MA3 & $\begin{array}{l}\text { I think that the mountains have historical vestiges } \\
\text { (heritage ambience, places of historical and religious } \\
\text { interest) }\end{array}$ & 0.0186 & 0.0573 & 0.0489 \\
\hline MA7 & $\begin{array}{l}\text { I think that the mountains have well-appointed } \\
\text { accommodation and restaurants (or similar) }\end{array}$ & 0.0321 & 0.0364 & 0.0414 \\
\hline LA2 & I think that MP food is safe & 0.1485 & 0.0490 & 0.0364 \\
\hline MFA2 & $\begin{array}{l}\text { I think that the mountains, as a tourism destination, } \\
\text { provide delicious food }\end{array}$ & 0.0529 & 0.0537 & 0.0337 \\
\hline LA18 & I think that MP food provides appealing flavors & 0.1555 & 0.0367 & 0.0240 \\
\hline $\mathrm{LA}_{4}$ & I think that eating MP food gives me pleasure & 0.0719 & 0.0342 & 0.0228 \\
\hline MA2 & $\begin{array}{l}\text { I think that the mountains have special village culture } \\
\text { (friendly people) }\end{array}$ & 0.0571 & 0.0367 & 0.0205 \\
\hline MFA1 & $\begin{array}{l}\text { I think that the mountains, as a tourism destination, } \\
\text { provide rich food culture }\end{array}$ & 0.0067 & 0.0407 & 0.0069 \\
\hline
\end{tabular}


Table 11 Purchase intention (PI) as a function of the Mountain attractiveness (MA), Mountain food attractiveness (MFA) and Mountain Product label attitude (LA) items. Regression coefficients corresponding to null values in the LASSO regression.

\begin{tabular}{l|l|l|l|}
\hline Code & Items & LM Coef & Ridge Coef \\
\hline LA9 & I like what MP label stands for [MP = mountain product] & -0.0286 & 0.0304 \\
\hline MFA4 & $\begin{array}{l}\text { I think that the mountains, as a tourism destination, provide traditional food } \\
\text { culture }\end{array}$ & -0.0076 & 0.0285 \\
\hline MA9 & I think that the mountains have convenient transportation & -0.0277 & 0.0073 \\
\hline MFA7 & I would like to travel to the mountains for food tourism & -0.1067 & 0.0055 \\
\hline LA10 & I think that MP food is hygienic & -0.0068 & 0.0088 \\
\hline MFA6 & I would like to (re)visit the mountains to explore different local foods & -0.0290 & 0.0136 \\
\hline LA7 & I think that eating MP food makes me feel happy & 0.0620 & 0.0193 \\
\hline MA8 & $\begin{array}{l}\text { I think that the mountains have good services and facilities (attractions, } \\
\text { mountain sports facilities) }\end{array}$ & 0.0564 & 0.0209 \\
\hline LA13 & MP label is an attractive label & 0.0109 & 0.0204 \\
\hline LA14 & I think that eating MP food changes my mood positively & -0.0552 & -0.0062 \\
\hline MA1 & $\begin{array}{l}\text { I think that the mountains have a unique eco-environment (climate, } \\
\text { cleanness) }\end{array}$ & -0.0507 & 0.0193 \\
\hline LA6 & I think that I am fascinated by MP food & 0.0269 & 0.0331 \\
\hline LA17 & I think that eating MP food makes me feel excited & -0.1069 & -0.0000 \\
\hline LA12 & I think that MP food contains good quality ingredients & -0.1373 & -0.0101 \\
\hline LA3 & I think that MP food is tasty & -0.1430 & 0.0018 \\
\hline MA6 & I think that the mountains have well-developed environment management & 0.0002 & 0.0122 \\
\hline MFA5 & I think that the mountains, as a tourism destination, provide diverse food & 0.0685 & 0.0273 \\
\hline LA8 & I think that MP food provides good nutrition & 0.0314 & 0.0195 \\
\hline LA5 & I think that MP food contains a variety of ingredients & -0.0871 & -0.0027 \\
\hline LA15 & I think that MP food provides a high standard of quality & -0.0714 & 0.0087 \\
\hline
\end{tabular}

consumer choice (Brun et al. 2020). Apparently, consumers appreciate the label because it embodies the features and characteristics they crave in mountain foodstuffs: taste, good nutrition, safety, appealing flavors, variety and good quality ingredients. It also embodies personal motivations and positive associations related to mountain food consumption, such as health and hedonic aspects. This broad set of needs and motivations plays a crucial role in shaping consumers' holistic experience and influencing their intention to taste mountain products sourced through different commercial channels (farm shop, mountain hut, specialty food shop, supermarket), or even to actively and purposefully look for them.

Additional contextual variables, such as age, in particular, can influence consumers' behavior. The estimation results show that age has a positive effect on purchase intentions. This result confirms and generalizes findings by Mazzocchi et al. (2021), who studied consumers' attitude towards mountain cheese. In particular, younger consumers (18-24) show significantly lower average values in both the purchase intention and the label attractiveness constructs. This means that, on the one hand, it might be preferred to focus on young consumers to build a new consensus and enlarge the consumer base; while on the other hand, marketing actions can focus on middle-aged consumers to be more effective in the short term and consolidate existing market shares.

Moreover, in contrast to previous work (Nam et al. 2020), purchase intention showed to be higher among consumers with a mid-level income. This counterintuitive result can be related to the perception of the mountain product as an expensive but not luxury good. This result can also guide the development of specific marketing actions to change product perception. The positive effect of product knowledge on the three considered constructs supports the intuition that active advertising strategies would potentially benefit mountain food products and producers. Lastly, but this represents only an indirect effect on purchase intentions, people living in the provinces of Pordenone, Udine, and Trieste show a lower average value of the mountain attractiveness construct residents in the province of Gorizia. This information suggests that optimal marketing initiatives should also consider the geographical origin of consumers and consequently be adapted and differentiated to exploit existing consensus (focusing on consumers residing in Gorizia) or to attract and capture new consumers (focusing on consumers from the other provinces). 
Finally, the analysis enabled the identification of the items that better explain purchase intentions. Out of the 37 items describing the MA, MFA and LA constructs, the results highlight the prominent role of the 17 items reported in Table 10. Therefore, marketing and development actions should mainly focus on these aspects. Regarding the elements that make the mountain more attractive, the results suggest leveraging on the beauty of landscapes, cultural and historical local assets, quality of accommodation and restaurants, friendly hospitality, and, not least, local specialties such as good food. Indeed, mountains as food-tourism destinations are mainly appreciated because they provide delicious and unique food, as well as a rich food culture, to the point that consumer-tourists crave to return to the mountains to enjoy their local food and recommend it to other people (family and friends). The label seems to be quite effective in embodying some personal needs and motivations, such as searching for safe food and appealing flavors, the craving and the pleasure of eating mountain food, and health reasons.

\section{Conclusions}

Our research aims at exploring the attractiveness of the mountain product label for consumers, considering both the attitude towards the label itself and purchase intentions. It proposes a research model of the relationships between four latent constructs mountain attractiveness, mountain food attractiveness, MP label attitude, and purchase intention - which have been tested, confirming the statistical relevance of the relationships.

All 47 items selected to describe the latent constructs are suitable for this purpose. We also find that, among the 37 items describing MA, MFA and LA constructs, 17 can be leveraged in designing mountain development strategies. According to the results of our analysis, consumers appreciate mountain products for their capacity to embed characteristics and meanings which directly recall the place of production. Consequently, tourism marketing actions should promote at once, and as a whole, traditional

\section{References}

Alderighi M, Bianchi C, Lorenzini E (2016) The impact of local food specialities on the decision to (re)visit a tourist local products and the territory. Some contextual variables (age, income, province of residence, kind of mountain knowledge, and mountain product knowledge) can also play an essential role in defining market segmentation. Knowing more about preferences and needs of consumers may support producers and local operators tailoring different policies for targeted segments to improve consumer satisfaction and increase revenue. Adopting more efficient marketing strategies and constructing brand awareness is essential to strengthen mountain products' competitiveness, support local food systems and economies, and promote resilience among rural communities.

While the sample size and composition proved to be quantitatively and qualitatively appropriate for the scope of our analysis, the spatial dimension of our research clearly limits the applicability and extention of the results outside the study area. Hence, replication of the investigation on different geographical areas may allow for a broader generalization of the results. For this reason, further research should be conducted in other regions for comparison, both in Italy and in other EU countries. Furthermore, the attractiveness and limitations of the EU label for mountain businesses and the economic impact should also be investigated.

\section{Acknowledgements}

This research was financially supported by the Department of Agricultural, Food, Environmental and Animal Sciences, University of Udine, Italy.

Open Access This article is distributed under the terms of the Creative Commons Attribution 4.0 International License

(http://creativecommons.org/licenses/by/4.0/), which permits unrestricted use, distribution, and reproduction in any medium, provided you give appropriate credit to the original author(s) and the source, provide a link to the Creative Commons license, and indicate if changes were made.

destination: Market-expanding or business-stealing?. Tour Manage 57: 323-333. 
https://doi.org/10.1016/j.tourman.2016.06.016

Ajzen I (1985) From intentions to actions: A theory of planned behavior. In: Kuhl J \& Beckmann J (eds.), Action Control From Cognition to Behaviour (11-39). Berlin: Springer. https://doi.org/10.1007/978-3-642-69746-3_2

Ajzen I (1991) The theory of planned behavior. Organizational Behavior and Human Decision Processes 50(2): 179-211. https://doi.org/10.1016/0749-5978(91)90020-T

Ajzen I, Fishbein M (1980) Understanding Attitudes and Predicting Social Behavior. Englewood Cliffs, NJ: PrenticeHall.

Balmer JMT, Chen W (2016) Corporate heritage tourism brand attractiveness and national identity. J Prod Brand Manage 25(3): 223-238.

https://doi.org/10.1108/JPBM-08-2015-0959

Baritaux V, Tebby C, Revoredo-Giha C (2011) How well do food retailers know their customers? The case of mountain food products in Europe. J Chain and Network Sci 11(3): 223-234. https://doi.org/10.3920/JCNS2011.x198

Bentivoglio D, Savini S, Finco A, et al. (2019) Quality and origin of mountain food products: the new European label as a strategy for sustainable development. J Mt Sci 16(2): 428-440. https://doi.org/10.1007/s11629-018-4962-x

Bonadonna A, Duglio S (2016) A Mountain Niche Production: The Case of Bettelmatt Cheese in the Antigorio and Formazza Valleys (Piedmont-Italy). Quality-Access to Success 17(150): 80-86.

Bonadonna A (2016) What Does the Optional Quality Term "Mountain Product" Involve? The Biellese Mountain (NorthWest Italy) Farmers' Opinions. Mediterranean J Soc Sci 7(1): 18-23. https://doi.org/10.5901/mjss.2016.v7n1p18

Bonadonna A, Peira G, Giachino C, Molinaro L (2017) Traditional Cheese Production and an EU Labeling Scheme: The Alpine Cheese Producers' Opinion. Agriculture 7(8): 65. https://doi.org/10.3390/agriculture7080065

Bonadonna A, Peira G, Varese E (2015) The European Optional quality term "mountain product": hypothetical application in the production chain of a traditional dairy product. QualityAccess to Success 16 (144): 99-104.

Brida JG, Osti L, Barquet A (2010) Segmenting resident perceptions towards tourism - A cluster analysis with a multinomial logit model of a mountain community. Int $\mathrm{J}$ Tour Res 12(5): 591-602. https://doi.org/10.1002/jtr.778

Brun F, Zanchini R, Mosso A, Di Vita G (2020) Testing consumer propensity towards novel optional quality terms: An explorative assessment of "mountain" labelled honey. AIMS Agriculture and Food 5(2): 190-203. https://doi.org/10.3934/agrfood.2020.2.190

Campbell JM, Fairhurst AE (2016) Reducing the intention-tobehaviour gap for locally produced foods purchasing: The role of store, trust, and price. Int J Retail Distrib Manage 44(5): 508-523. https://doi.org/10.1108/IJRDM-08-2015-0121

Charters T, Saxon E (2007) Tourism and Mountains: A Practical Guide to Good Practice. Paris: UNEP.

Chekalina T, Fuchs M, Lexhagen M (2018) Destination Brand Promise: the Core of Customer-Based Brand Equity Modeling. Tour Anal 23: 93-107. https://doi.org/10.3727/108354218X15143857349800

Cheng TM, Wu HC, Huang LM (2013) The influence of place attachment on the relationship between destination attractiveness and environmentally responsible behavior for island tourism in Penghu, Taiwan. J Sustainable Tour 21(8): 1166-1187. https://doi.org/10.1080/09669582.2012.750329

Chien MC (2017) An empirical study on the effect of attractiveness of ecotourism destination on experiential value and revisit intention. Appl Ecol Environ Res 15(2): 43-53. https://doi.org/ 10.15666/aeer/1502_043053

Choe JYJ, Kim SS (2018) Effects of tourists' local food consumption value on attitude, food destination image, and behavioral intention. Int $J$ Hosp Manage 71: 1-10. https://doi.org/10.1016/j.ijhm.2017.11.007

Costell E, Tárrega A, Bayarri S (2010) Food acceptance: the role of consumer perception and attitudes. Chemosensory Percept 3: 42-50. https://doi.org/10.1007/s12078-009-9057-1

Couper MP (2000) Web surveys: a review of issues and approaches. Public Opin Q 64: 464-494.

Debarbieux B, Price MF (2008) Representing mountains: From local and national to global common good. Geopolitics 13(1): 148-168. https://doi.org/10.1080/14650040701783375

De Meo I, Paletto A, Cantiani MG (2015) The attractiveness of forests: preferences and perceptions in a mountain community in Italy. Ann For Res 58(1): 145-156.

http://doi.org/10.15287/afr.2015.308

Diallo MF (2012) Effects of store image and store brand priceimage on store brand purchase intention: Application to an emerging market. J Retailing Consum Serv 19: 360-367. https://doi.org/10.1016/j.jretconser.2012.03.010

Edwards AL, Kenney KC (1946) A comparison of the Thurstone and Likert techniques of attitude scale construction. J Appl Psychol 30(1): 72. https://doi.org/10.1037/hoo62418

Elbedweihy AM, Jayawardhena C, Elsharnouby MH, Elsharnouby TH (2016) Customer relationship building: The role of brand attractiveness and consumer-brand identification. J Bus Res 69: 2901-2910. https://doi.org/10.1016/j.jbusres.2015.12.059

Finco A, Bentivoglio D, Bucci G (2017) A label for mountain products? Let's turn it over to producers and retailers. Quality-Access to Success 18(2): 198-205.

Fishbein M (1963) An investigation of the relationship between beliefs about an object and the attitude toward that object. Hum Relations 16: 233-239. https://doi.org/10.1177\%2Fo01872676301600302

Fishbein M, Ajzen I (1975) Belief, Attitude, Intention, and Behavior: An Introduction to Theory and Research. Reading, MA: Addison-Wesley.

Friedman J, Hastie T, Tibshirani R (2010) Regularization Paths for Generalized Linear Models via Coordinate Descent. J Stat Softw 33(1): 1-22. www.jstatsoft.org/v33/io1

Gritz AS, Reinhold N, Batinic B (2002) Online panels. In: Batinic B, Reips UD, Bosnjak M, Werner A (eds.), Online Social Sciences. Seattle: Hogrefe. pp 27-47.

Homer PM, Kahle LR (1988) A structural equation test of the value-attitude behavior hierarchy. J Pers Soc Psychol 54: 638646. https://doi.org/10.1037/0022-3514.54.4.638

Johnston J, Szabo M (2011) Reflexivity and the whole foods market consumer: The lived experience of shopping for change. Agric Hum Values 28(3): 303-319. https://doi.org/10.1007/s10460-010-9283-9

Kim JH, Ritchie JRB, McCormick B (2012) Development of a Scale to Measure Memorable Tourism Experiences. J Travel Res 51(1): 12-25. https://doi.org/10.1177\%2Foo47287510385467

Kim YG, Eves A (2012) Construction and validation of a scale to measure tourist motivation to consume local food. Tour Manage 33: 1458-1467.

https://doi.org/10.1016/j.tourman.2012.01.015

Kim Y, Han H (2010) Intention to pay conventional-hotel prices at a green hotel-a modification of the theory of planned behavior. J Sustainable Tour 18(8): 997-1014. https://doi.org/10.1080/09669582.2010.490300

Kuščer K, Mihalič T (2015) The impact of innovativeness on mountain destination development. In: Pechlaner $\mathrm{H}$, Innerhofer $\mathrm{E}$ (eds.), Competence Based Innovation in Hospitality and Tourism. Surrey, UK: Gower Publishing.

Laroche M, Brisoux JE (1989) Incorporating Competition into Consumer Behavior Models: The Case of the AttitudeIntention Relationship. J Econ Psychol 10: 343-362. https://doi.org/10.1016/0167-4870(89)90029-9

Lassoued R, Hobbs JE (2015) Consumer confidence in credence attributes: The role of brand trust. Food Policy 52: 99-107. https://doi.org/10.1016/j.foodpol.2014.12.003

Liang RD (2016) Predicting intentions to purchase organic food: the moderating effects of organic food prices. Br Food J 118(1): 
183-199. https://doi.org/10.1108/BFJ-06-2015-0215

Lin CY, Marshall D, Dawson J (2009) Consumer attitudes towards a European retailer's private brand food products: an integrated model of Taiwanese consumers. J Mark Manage 25(9-10): 875-891. https://doi.org/10.1362/026725709X479273

Martins N, Ferreira ICFR (2017) Mountain food products: A broad spectrum of market potential to be exploited. Trends Food Sci Technol 67: 12-18. https://doi.org/10.1016/j.tifs.2017.06.013

Matei E, Stănciou FA, Vijulie I, et al. (2019) Attractiveness and competitiveness of the Romanian Carpathian mountains destinations: a study of perception of generation Y. J Environ Tour Analyses 7(1): 5-15.

Mazzocchi C, Orsi L, Sali G (2021) Consumers' Attitudes for Sustainable Mountain Cheese. Sustainability 13: 1743. https://doi.org/10.3390/su13041743

McMorran R, Santini F, Guri F, et al. (2015) A mountain food label for Europe?. J Alpine Res | Revue de géographie alpine [Online]. https://doi.org/10.400o/rga.2654

Mitchell AA \& Olson JC (1981) Are Product Beliefs the Only Mediator of Advertising Effect on Brand Attitude?. J MarkRes 18(3): 318-332.

Murphy P, Pritchard MP, Smith B (200o) The destination product and its impact on traveller perceptions. Tour Manage 21: 43-52. https://doi.org/10.1016/So261-5177(99)ooo80-1

Nam K, Lim H, Ahn BI (2020) Analysis of consumer preference for milk produced through sustainable farming: The case of mountainous dairy farming. Sustainability 12(7): 3039 . https://doi.org/10.3390/su12073039

Navrátil J, Pícha K, Knotek J, et al. (2013) Comparison of attractiveness of tourist sites for ecotourism and mass tourism: the case of waters in mountainous protected areas. Tourismos: an International Multidisciplinary Journal of Tourism 8(1): 35-51.

Nepal SK, Chipeniuk R (2005) Mountain tourism: Toward a conceptual framework. Tour Geogr 7(3): 313-333.

https://doi.org/10.108o/14616680500164849

Oh H, Fiore AM, Jeoung M (2007) Measuring Experience Economy Concepts: Tourism Applications. J Travel Res 46: 119-132. https://doi.org/10.1177\%2F0047287507304039

Opačić VT, Banda A (2018) Alternative Forms of Tourism in Mountain Tourism Destination: A Case Study of Bjelašnica (Bosnia and Herzegovina). Geogr Pannonica 22(1): 40-53. https://doi.org/10.5937/gp22-16621

Quan S, Wang N (2004) Towards a structural model of the tourist experience: an illustration from food experiences in tourism. Tour Manage 25: 297-305.

https://doi.org/10.1016/So261-5177(o3)oo130-4

Rajh E (2002) Development of a scale for measuring CustomerBased Brand Equity. Ekonomski Pregled 53 (7-8): 770-781.

R Core Team (2021) R: A Language and Environment for Statistical Computing. Vienna, Austria: R Foundation for Statistical Computing. www.R-project.org

Revelle W (2019) Psych: Procedures for Personality and Psychological Research. Evanston, IL: Northwestern University.

https://CRAN.R-project.org/package=psych Version = 1.9.12.

Rosseel Y (2012) Lavaan: An R package for structural equation modeling. J Stat Softw 48(2): 1-36. www.jstatsoft.org/v48 /io2

Sanjuan AI, Khliji S (2016) Urban consumers' response to the EU food mountain labelling: an empirical application in
Southern Europe. New Medit 15(1): 72-81.

Schäufele I, Hamm U (2018) Organic wine purchase behaviour in Germany: Exploring the attitude-behaviour-gap with data from a household panel. Food Qual Prefer 63: 1-11. https://doi.org/10.1016/j.foodqual.2017.07.010

Silva C, Kastenholz E, Abrantes JL (2018) Linking mountain image with place-attachment. J Spat Organ Dyn 6(2): 140-152. Silva C, Kastenholz E, Abrantes JL (2013) Place-attachment, destination image and impacts of tourism in mountain destinations. Anatolia: An Int J Tour Hosp Res 24(1): 17-29. https://doi.org/10.1080/13032917.2012.762312

Simonson I, Tversky A (1992) Choice in Context: Tradeoff Contrast and Extremeness Aversion. J Mark Res 29: 281-295. https://doi.org/10.1177\%2Fo02224379202900301

So KKF, King C, Hudson S, Meng F (2017) The missing link in building customer brand identification: The role of brand attractiveness. Tour Manage 59: 640-651. https://doi.org/10.1016/j.tourman.2016.09.013

Spears N, Singh SN (2004) Measuring Attitude Toward the Brand and Purchase Intentions. J Curr Issues Res Advert 26(2): 53-66.

https://doi.org/10.1080/10641734.2004.10505164

Stamboulis Y, Skayannis P (2003) Innovation Strategies and Technology for Experience-Based Tourism. Tour Manage 24: 35-43. https://doi.org/10.1016/So261-5177(02)00047-X

Taher SHM, Jamal SA, Sumarjan N, Aminudin N (2015) Examining the structural relations among hikers' assessment of pull-factors, satisfaction and revisit intentions: The case of mountain tourism in Malaysia. J Outdoor Recreat Tour 12: 82-88. https://doi.org/10.1016/j.jort.2015.11.012

Thøgersen J, Grunert-Beckmann SC (1997) Values and attitude formation towards emerging attitude objects: From recycling to general, waste minimizing behavior. Adv Consum Res 24: 182-189.

Tikkanen I (2007) Maslow's hierarchy and food tourism in Finland: five cases. Br Food J 109(9): 721-734. https://doi.org/10.1108/00070700710780698

Vázquez R, Belén del Río A, Iglesias V (2002) Consumer-based Brand Equity: Development and Validation of a Measurement Instrument. J Mark Manage 18(1-2): 27-48. https://doi.org/10.1362/0267257022775882

Vengesayi S, Mavondo FT, Reisinger Y (2009) Tourism Destination Attractiveness: Attractions, Facilities, and People as Predictors. Tour Analysis 14: 621-636. https://doi.org/10.3727/108354209X12597959359211

Wang EST (2015) Effect of food service-brand equity on consumer-perceived food value, physical risk, and brand preference. Br Food J 117(2): 553-564. https://doi.org/10.1108/BFJ-09-2013-0260

Wu SI, Chen JY (2014) A model of green consumption behavior constructed by the theory of planned behavior. Int J Mark Stud 6(5): 119. https://doi.org/10.5539/ijms.v6n5p119

Zafar QUA, Rafique M (2012) Impact of Celebrity Advertisement on Customers' Brand Perception and Purchase Intention. Asian J Bus Manage Sci 1(11): 53-67.

Zhu Q, Li Y, Geng Y, Qi Y (2013) Green food consumption intention, behaviors and influencing factors among Chinese consumers. Food Qual Prefer 28(1): 279-286. https://doi.org/10.1016/j.foodqual.2012.10.005

Zuliani A, Esbjerg L, Grunert KG, Bovolenta S (2018) Animal welfare and mountain products from traditional dairy farms: How do consumers perceive complexity?. Animals 8(11): 207. https://doi.org/10.3390/ani8110207 